\title{
German Shorthaired Pointer
}

National Cancer Institute

\section{Source}

National Cancer Institute. German Shorthaired Pointer. NCI Thesaurus. Code C53867.

The German Shorthaired Pointer is a clean-cut, well-balanced, hunting dog with a chiseled head and large nose. The muzzle is long, but not pointed, and it has a short, dense coat that comes in solid liver or liver and white, patched, ticked or roan. Height: 21-25 inches (53-64 cm.) Weight: 45-70 pounds (20-32 kg.) 